\title{
Multi-Perspective Approach to Identify Strategic Issues: A Case Study of Traditional Market Management at West Java
}

\author{
Arip Rahman Sudrajat, Edi Setiawan, \\ Fepi Febianti, Rika Kusdinar, Lalas Sulastri \\ Sekolah Tinggi Ilmu Administrasi (STIA) Sebelas April Sumedang (email: arip.rs84@gmail.com)
}

\begin{abstract}
Traditional market management requires a precise and measurable system given the important role of the market in supporting the local economy on the one hand, and the complexity of the problems to be faced on the other. Efforts are needed to ensure a targeted traditional market management system, among which is oriented towards the identification and stewardship of appropriate strategic issues. This qualitative research is carried out to apply a multi-perspective approach that is considered accommodative to the variety of variables, in mapping the strategic value of various problems that arise in the management of traditional markets. The research was conducted in the traditional markets of Bantarujeg, West Java and produced strategic mapping of problem groups related to administrative, financial, organizational and traditional market development.
\end{abstract}

\section{Keywords:}

traditional market; problem identification; multi-perspective approach

\section{Introduction}

Along with the dynamics of global society change today, the community-based economy in various countries still rely on buying and selling activities in shopping centers, both shopping centers are managed with modern and traditional systems.

Traditional market as a form of independent community-based retail business activity is an important part of the populist economic system in Indonesia. Despite the intense competition with the growth of modern shopping centers, the traditional market role in ensuring the ongoing economic movement within local communities is one thing that cannot be denied. Appropriate and measurable traditional market management is a key to increasing market effectiveness in increasing its contribution to economic growth. In the context of Indonesia, administratively, traditional markets are defined as markets built and managed by the central government, regional governments, state-owned enterprises, state- 
owned enterprises and private parties whose businesses are kiosks, shops, tents and stalls owned or managed by small, medium, community self-help which process of buying and selling done through bargaining process (Kumar \& Ruan, 2006).

The traditional foundation ideas in marketing, including the ever-present marketing mix (product, price, place and promotion) continued to be concrete product centered (Cholwill, 2011). The principle of marketing is to supply strategies the enables of the firm produce supplies and services that meet consumers' needs and wants while enduring commercial enough to meet the manufacturers' objectives. The effectiveness of marketing approaches such as transactional, segmentation, relationship or experiential marketing in influencing the consumers' decision is largely dependent on business understanding, and management of the marketing mix (Bourlakis, Papagiannidis, \& Li, 2009).

This explanation shows the recognition of the role of traditional markets in supporting economic activity in Indonesia. This contribution space refers to the important role of traditional markets in economic growth, especially retail trade activities. This is in line with a number of studies that highlight the important role of traditional markets in a number of functions. First, the distribution function, the market serves to close the distance between consumers and producers in carrying out transactions (Rahman, Ismail, \& Ariffin, 2016). In this function, the market also plays a role in facilitating the distribution of goods and services from producers to consumers (Hwa \& Chin, 2012). Distribution is a traditional marketing strategy that is pivotal because irrespective of the effectiveness of the production process or the quality of the products that emerges from that process (Siebers, Aickelin, Celia, \& Clegg, 2011). All the advantages accrued from efficient process and the quality of the product is lost if the goods are not available in the market where they can be accessed by the consumers. Where there is laxity in the distribution strategy, all the gain made through effective and efficient production and promotion are lost. While the successful management of the marketing mix is critical, a business organization's marketing approach can make or undermine the objectives of the manufacturer (Fendiani \& Tandiono, 2016).

Second, the function of traditional markets as the formation of price/value of a good or service, adjusted to demand and supply that occurred in the market, after the agreement then formed a price/price range (Ruhiiga, 2012). One critical aspect of the description of price "that which is given in return for a product in a commercial exchange" (Cholwill, 
2011). If the transaction is not a commercial exchange, then the value given in return for the product cannot be said to be price. The significance of price in traditional marketing strategy is not primarily concerned with creating value (Gonzalez \& Waley, 2013). Rather, it could be said the marketing activity involved with capturing, or "harvesting" the value created by the other marketing activities. In addition, price as a traditional marketing activity is fundamentally different from others because it produces revenue while others produce costs. This is main significance of pricing in the whole concept of marketing. Where the pricing strategy an organization is wrong, the whole system of is doomed to collapse from production to marketing (Kumar \& Ruan, 2006).

Third, traditional markets serve as a means of promoting/introducing a product from production to the local community (Willcocks, 2002). The role of promotion is to call attention to a product or service, and build awareness of it, usually with a focus on key benefits, with the ultimate aim of influencing purchasing decisions. Promotion exists both to inform and create awareness; and it is an essential aspect of marketing in competitive markets; promotion includes advertising, public relations, and marketing communications. Nevertheless, the important role of this traditional market is also consistent with the dynamic challenges that hinder any development effort.

A number of studies show various challenges in organizing and developing trading activities in traditional markets. One of the biggest challenges is competition with modern markets with large capital and development resources (Coe \& Bok, 2014). In addition, the challenge also comes from changes in people's purchasing power (Ruhiiga, 2012) that tend to be influenced by the perception of satisfaction and assessment of service standards. Changes also occur in people's consumption behaviors that are influenced by sharp social class distinctions, thus tending to limit the range of traditional market consumers in the middle- and low-income class (Gonzalez \& Waley, 2013). Changes in consumption behavior that tend to override the choice to shop in traditional markets are also detected in the younger generation who tend to be more critical of the fulfillment of their needs (Prabowo \& Rahardi, 2015), these findings indicate that there are still many traditional markets with minimum service quality. Variety of challenges that can confront efforts to maintain and develop the existence of this traditional market shows the urgency of improving the quality of management of traditional markets to be more strategic, effective and efficient. 
Traditional market management in the development of the retail industry rests on a historically and culturally changing management institution (Matjomane, 2013), which is followed by a change in the challenges faced by each management period. Socio-economic studies show initially that traditional market management is characterized by non-formal community management. Later on, traditional market management is directed to the government's active role (both at the national and local levels) formally fixing as well as capitalizing significantly. Capitalization in traditional market management allows for more connectivity among stakeholders, including producers (farmers and industry), distributors and consumers (Sunanto, 2014). In addition, proper management also has a direct impact on increasing public purchasing power (Rahardi, 2012). While non-formal management has an unorganized tendency can be consequential in many losses of potential economic benefits (Ruhiiga, 2012). Therefore, a good management system is required with a programmed management strategy with service-oriented optimization and dynamic problem solving.

The aim of every organized move is the achievement of goals that can be tangible to solve the problem (Head \& Alford, 2013). Strategic traditional market management should be based on every implementation of the program on problem-solving efforts. In management strategy, identification and mapping of related and relation issues in the implementation of each stage of management, both at the stage of formulation, implementation and evaluation of strategy (Wongleedee, 2015). At each stage, the process and the outcome of the identification of the problem potentially becomes the determinant of the measurement of the objective capability, in addition it influences to the effectiveness of the concrete management program. A number of studies in traditional market management strategies are conducted with various approaches by putting the problem identification process as the main focus. Most research mapping problems in traditional market management based on consumer's point of view (Wang, Ko, \& Liu, 2016), both in the level of satisfaction and public perception of the fulfillment of their needs by traditional markets. From the things that indicated there is still a gap mapping problem that has not deeply done, that is putting the point of view of the manager. Identification of problems from the standpoint of traditional market managers allows mapping to be carried out more in line with management needs. 
Traditional market management in an organized manner requires a management organizational structure that touches on various aspects of market management. Every part of the structure represents the personal and professional role of market managers. In other words, each unit has the tasks and responsibilities that underpin the success of market management in addressing any issues. Thus, a problem-solving approach that accommodates such roles is needed, one of which is a multi-perspective approach to problem mapping. A multi-perspective approach is important in the development of management strategies to ensure the representation of the various roles involved in a management system (Willcocks, 2002). In addition, multi-perspective alignment provides space for every interest in management to gain focus of attention (Head \& Alford, 2013).

In this research, the problem identification process in the management of traditional markets is formally managed by the local government. By involving the perspectives of a number of market management units, this research uses a multi-perspective approach to identify and clarify the problems had in market management strategies. The findings in this study are expected to provide an overview of the importance of ensuring the issues that focuses on the management system.

\section{Methods}

This qualitative research is applied on a case study conducted in Bantarujeg Traditional Market, at Majalengka Regency, West Java Province. By involving four research subjects (as respondents who are part of the organization of the market management agency, this research data is also verified by collecting data by observation, review policy and administrative file review. The four subjects of this study are: 1) head of market management agency (General manager); 2) head of unit for maintenance and supervision affairs; 3) head of unit for empowerment and development affairs; and 4) general assistant.Referring to the implementation stage of the case study developed by $\mathrm{Yin}^{19}$, this research involves the process of case mapping, data collection, evaluation and data analysis harmonized with the character of a comprehensive multi-perspective approach. Starting with: 1) determining the focus of the problem and identifying the role of each research subject; 2) mapping problems using interview instruments (consisting of 24 open questions); 3) deepening of the perspective of each research subject; 4) clarifying data; 5) analyzing the multi-perspective analysis. At each 
stage, the research subjects representing different units within the market management system, are the main sources of information. While the observation data and secondary sources directed to assess the consistency of resource persons on mapping problems in perspective. Then later in the final section, the researchers obtained a picture of the mapped problem of its strategic value in the management of Bantarujeg Traditional Market.

\section{Results and Discussion}

The results of this study were presented in the achievements and findings obtained at each stage of problem identification. Qualitatively, the interpretation of each of the findings obtained is then compiled into a multi-perspective analysis that leads to the meaning of how far the strategic value of the issues is revealed.

a. Identify the role of the research subject

Gathering the information from resource persons and clarifying the organizational regulations that have been established, the description of the role of each subject in the management of the market are described in Table 1. This role demonstrates the importance of the position and contribution of each subject in ensuring a healthy economic activity in the market.

\section{Table 1.}

The role of each research subject in the management of Bantarujeg tradiotional market

\begin{tabular}{ll}
\hline Subject & Role in market management \\
\hline General & $-\quad$ Conduct market management in accordance with applicable \\
& -
\end{tabular}




\begin{tabular}{ll}
\hline Subject & Role in market management \\
\hline $\begin{array}{l}\text { General } \\
\text { assistant. }\end{array}$ & Carry out assistant duties and supporting roles for each \\
implementing unit.
\end{tabular}

The study of the roles of each subject in market management shows the difference in breadth and depth of potential contribution to each subject. The role of general manager are more than others but at the level of the drafter and coordinator with outsiders. While the roles of two head units more focused on the function of internal coordination in their respective affairs. The roles of implementation with cross-sector contribution is more indicated on general assistant roles.

b. Mapping and focusing issues

In order to uncover the problems experienced by each subject, a mapping questionnaire (consisting of 24 open questions) that findings mapped the perspective of each subject to the problem.

Table 2.

Sample question of problem mapping questionnaire

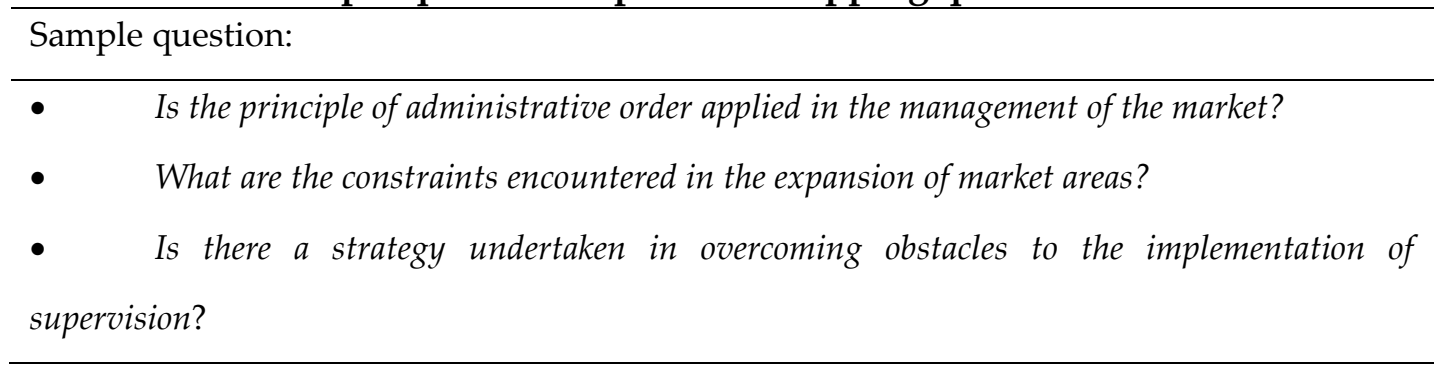

Based on mapping process, revealed a number of problems perceived, realized even faced by every subject while performing its role in market management. The identification and grouping of problems is based on the general character of the problem areas, namely issues related to administrative management, financial management, organizational arrangements and implementation of market development programs. The results are shown that the most common problems faced by each subject was the problem in the implementation of the development program(as presented in Figure 1). 
Figure 1.

Problem group mapping

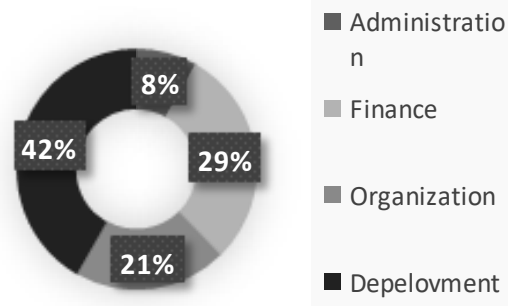

c. A deeper review of the various perspectives on the focus of issues

After obtaining the dominant problem groups found in market management according to perspective of each subject, a deepening perspective was conducted to gain the focus of the real problem(as presented in table 3).

Table 3.

The result of identifying the focus of the problems

\begin{tabular}{lc}
\hline \multicolumn{2}{l}{ Focus on administrative issues } \\
\hline- & Formulation and scope of regulation of market management implementation \\
- & The mechanism of data collection of traders, visitors, and market assets \\
Focus on financial issues \\
\hline - & Various sources of levy set by market manager \\
- & Management and achievement of retribution and accountability targets \\
\hline Focus on maintenance and organizational issues \\
\hline - & Recruitment and management of human resources \\
\hline & Methods and effectiveness of surveillance of market activities \\
\hline Focus on Development issues \\
\hline- & Empowering managers and traders \\
\hline & Plan and execution of market area and capacity expansion \\
\hline
\end{tabular}

A further assessment of each problem in the form of a detailed focus of the problem developed from the perspective of each subject shows the technical dimensions of each problem group. These findings led to more factual and targeted identification of the problem. The results show that each problem group has a focus on the collaborative role that every subject should be careful to take.

d. Clarification and verification background data from the perspective of the issues

The results of data clarification with directed observation method to the field resulted in an indication of the conformity of the problems revealed by each subject with 
field conditions. In addition, reviewing the regulatory documents and implementing the policies also demonstrate consistency that can be accounted for. This finding is important to ensure that sustainable improvement is required in the market management system. It was almost certain that this urgency refers to the tendency that the existing management system but various problems are still emerging.

e. Multi-perspective analysis to determine the strategic issues.

Multi-perspective analysis was done by looking at the consistency of the focus of the problem that was revealed from the perspective of each subject. This consistency was then compared to subjects to obtain a picture of the strategic meaning of the problem. Problems those were realized by each subject indicate the strategic value it contains, as well as the urgency of the solution. By comparing the proportion of each problem in the perspective of each subject, a description of the dominant problem of the development program is obtained.

\section{Figure 2.}

Proportion of problem groups in the perspective of each subject

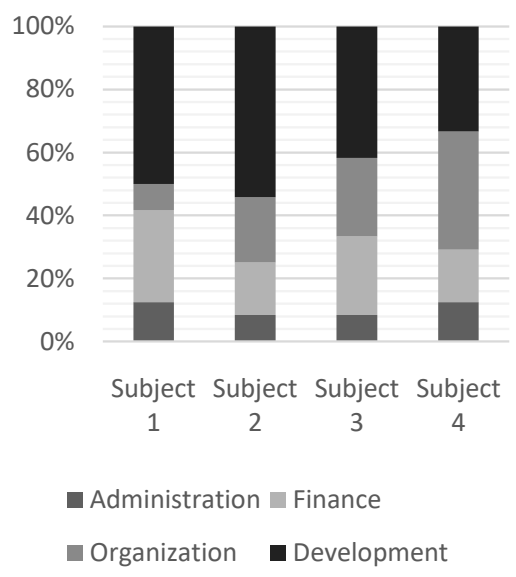

\section{Conclusion}

The results show that the problems associated with the implementation of market development programs, both the development of market areas and the development of market capacity was a dominant problem arises and was recognized almost every subject. Compared to the focus of other issues, it was only natural that development-related issues become so consistently dominant in all subject perspectives if they refer to development efforts that cannot run separately. It taken a multi-sector role to ensure the development 
program goes as planned. Thus the problems identified through the gradual and simultaneous stages of verification, ensuring the problems that were then established for formulated solutions, were not merely urgent issues but have a thorough impact on improved management systems. By formulating the right problem, it was expected that traditional market management can be directed and efficient.

\section{References}

\section{Books}

Bourlakis Bourlakis, M., Papagiannidis, S., \& Li, F. (2009). Retail spatial evolution: paving the way from traditional to metaverse retailing. Electronic Commerce Research, 9(1-2), 135-148.

Cholwill, M. (2011). Consumer behaviour in the traditional cruise market and implications for the sustainability of ocean cruising. Gabler Verlag: Springer Fachmedien Wiesbaden.

Coe, N. M., \& Bok, R. (2014). Retail transitions in Southeast Asia. The International Review of Retail, Distribution and Consumer Research 479-499.

Gonzalez, S., \& Waley, P. (2013). Traditional Retail Markets: The New Gentrification Frontier? Antipode, 45 (4), 965-983.

Head, B. W., \& Alford, J. (2013). Wicked Problems: Implications for Public Policy and Management. Administration and Sociaty.

Kumar, N., \& Ruan, R. (2006). On manufactures complementing the traditional retail channel with a direct online channel. Quantitative Marketing and Economics, 4 (5), 289323.

Sunanto, S. (2014). The Effects of Modern Food-Retail Development on Consumers, Producers, Wholesalers, and Traditional Retailers: The Case of West Java. Bulletin of Indonesian Economic Studies, 50(2), 290-291.

\section{Journal article}

Fendiani, A., \& Tandiono, R. (2016). Family Business and Managerial Ownership: The Effect on the degree of accounting conservatism practised in Indonesia listed firms. Pertanika Journal Social Science and Humanities, 24, 109-118. 
Hwa, Y. S., \& Chin, C. H. (2012). Using conjoint analysis to study consumers' choice of supermarkets. Jurnal Pengurusan, 91-100.

Prabowo, F. S., \& Rahardi, R. A. (2015). David vs. Goliath: Uncovering The Future of Traditional Markets in Indonesia. Mediterranean Journal of Social Sciences, 6 (5), 28-36.

Rahardi, R. A. (2012). Repeat consumption behaviour in traditional markets: Bandung and surrounding regions. Journal of Asian Behavioural Studies, 39 (1), 49-60.

Rahman, A. A., Ismail, N. A., \& Ariffin, Z. Z. (2016). From Green to Lean: Firms' Waste Management Practices and their impacts on business performence. Pertanika Journal Social Science and Humanities, 29-46.

Ruhiiga, T. M. (2012). Public transport and the decline of the traditional retail sector in South Africa. Journal of Human Ecology, 39(1), 49-60.

Ruhiiga, T. M. (2012). Public transport and the decline of the traditional retail sector in South Africa. Journal of Human Ecology, 39(1), 49-60.

Siebers, P., Aickelin, U., Celia, H., \& Clegg, C. (2011). Towards the development of a simulator for investigating the impact of people management practices on retail performance. Journal of Simulation, 5, 247-265.

Wang, H., Ko, K. H., \& Liu, H. (2016). Relationship between service quality and customer equity in traditional markets. Journal of Business Research, 69(9), 3827-3834.

Willcocks, S. G. (2002). Adopting a multi-perspective approach to the study of public sector managerial effectiveness. International Journal of Public Sector Management, 15 (4), $262-$ 280.

Wongleedee, K. (2015). Marketing mix and purchasing behavior for community products at traditional markets. Procedia-Social and Behavioral Sciences, 197, 2080-2085.

\section{Disertation}

Matjomane, M. D. (2013). Strategies used by street trader's organisations to influence trading policy and management in the city of Johannesburg. Doctoral Disertation. 